\title{
Constraining Design: Applying the Insights of Cognitive Work Analysis to the Design of Novel In-Car Interfaces to Support Eco-Driving
}

\author{
Craig K. Allison ${ }^{1}\left[\right.$. Neville A. Stanton ${ }^{2}$
}

Received: 26 April 2019 / Accepted: 18 January 2020 / Published online: 3 March 2020

(c) The Author(s) 2020

\begin{abstract}
The design with intent (DwI) toolkit assists designers in creating novel designs and interfaces. DwI, however, is not constrained to any degree, making it impossible to know whether the produced designs adequately account for users' needs. In contrast, cognitive work analysis (CWA) is a human factors research tool that seeks to map a system and account for users' needs, yet does not provide clear guidelines for progressing such analysis into workable designs with which users can interact. This paper seeks to present a proof-of-concept investigation to demonstrate that DwI can be suitably constrained and validated by insights gained from CWA. CWA, in turn, benefits by having a suitable toolkit for progressing insights. Two teams of individuals without design backgrounds were able to develop mock-up in-vehicle interfaces aimed at reducing fuel use. The teams were able to use DwI toolkit to articulate the genesis of their ideas, which in turn could be directly linked to system needs identified within CWA.
\end{abstract}

Keywords Design with intent $\cdot$ Cognitive work analysis $\cdot$ Interface design $\cdot$ Eco-driving

$\begin{array}{ll}\text { Abbreviations } \\ \text { CWA } & \text { Cognitive work analysis } \\ \text { DwI } & \text { Design with intent } \\ \text { HDD } & \text { Head-down display } \\ \text { HUD } & \text { Head-up display }\end{array}$

\section{Introduction}

Transport emissions, primarily carbon dioxide $\left(\mathrm{CO}_{2}\right)$ and nitrous oxides $\left(\mathrm{NO}_{x}\right)$ are the leading cause of air pollution in Britain [1]. Of this, road vehicles, specifically automobiles, are the biggest contributor, accounting for approximately $75 \%$ of the total transport-related greenhouse gas emissions [2]. Vehicle emissions are far from benign, having significant long-term health implications [3]. Exposure to vehicle emissions increases individuals' risk in developing a variety of respiratory disorders including asthma, bronchitis,

Craig K. Allison

Craig.Allison@solent.ac.uk

1 Solent University, East Park Terrace, Southampton SO14 OYN, UK

2 Transportation Research Group, University of Southampton, Boldrewood Innovation Campus, Southampton SO16 7QF, UK chronic obstructive pulmonary disease, pneumonia and upper respiratory tract infection [4]. In addition to the considerable negative impact vehicle emissions can have on human health, these emissions also have significant environmental impact and have been directly linked to anthropogenic climate change and changing global weather patterns $[5,6]$. With such significant and universally negative effects, finding ways to reduce the current high levels of vehicle emissions is a defining challenge of the twenty-first century, one which the automotive sector is keen to address $[7,8]$.

Whilst it is, at least currently, not possible to completely remove emissions from automotive transportation [9], emissions and the associated volume of fuel used can be significantly reduced as a consequence of driver behaviour change $[10,11]$. Previous research has suggested that vehicle emissions could be reduced by $5 \%-20 \%$ [12] with fuel usage reduced by between 5\% and 10\% [13] should drivers engage in more environmentally friendly driving behaviours. As has been previously argued, "There is little innately special about more environmentally friendly user behaviour: it's often simply about using a system effectively" [14]. Pursuing interventions to support a shift towards such driving behaviour and encouraging the adoption of more environmentally conscious driving styles are therefore justly warranted.

One approach to support the modification of driver behaviour is the design of interfaces that directly offer guidance 
on potential future actions and offer feedback on previous behaviours [15]. The design of new interfaces to encourage a greater awareness of resource use is not novel, and has been significantly pursued to reduce both household energy usage [16] and vehicle energy usage whilst driving [17]. Feedback devices can be successful at promoting positive behavioral change as users are, fundamentally, unaware of their energy consumption [18]. Consequently, individuals are unaware that they can, or indeed need, to take action to modify their behaviour. Previous research [19] has demonstrated that household energy use can be significantly reduced following targeted interventions and advice that directly accounts for specific user behaviours. This approach has also been documented to be successful within previous work within the automotive sector, primarily those targeting the uptake of eco-driving behaviours [20-22]. These studies have uniformly identified that significant fuel savings are possible following the provision of in-vehicle feedback devices that respond to driver actions.

\subsection{Designing Interfaces}

The development of interfaces to encourage environmentally conscious behaviour can be seen as placing the designer as a controller of human behaviour. Whilst this role could be seen as beyond designers remit, the design of objects has always had an irrefutable fundamental influence on subsequent activities [23, 24]. Whether the subject of the design is a desired physical object or an interface to direct or modify user behaviours, designers have an explicit role in influencing the decision-making process [14]. This approach is perhaps best popularized by Fabricant's (2009) phrasing that "Designers are in the behaviour business" [25]. The search for novel approaches to design is of growing interest to researchers [26, 27]. One design approach that may be of value in this pursuit is the design with intent (DwI) toolkit [25]. From a foundation within ecological psychology [28], DwI seeks to combine an understanding of human activities with affordance theory [29] with insights gained from prominent design theorists $[30,31]$ to offer a flexible approach to novel design. The approach is predicated on the view that behaviour can be directed by design [30], with design having an intrinsic role in suggesting and promoting desirable behaviours whilst simultaneously constraining and reducing the potential for undesirable behaviours to occur. DwI acts as a "Suggestion tool" [25], which seeks to inspire designers to develop novel solutions to problems.

The DwI approach is characterized by the use of 101 design cards, divided between 8 key lenses, each of which loosely corresponds to the theme of the cards. Many cards could fit into multiple lenses and the division between such lenses can often been seen as somewhat arbitrary [32]. The key lenses are Architectural, Errorproofing, Interaction, Ludic, Perceptual, Cognitive, Machiavellian, and Security. Table 1 presents a summary of the main themes of each of the lenses, as well as example cards from the toolkit lens. Each DwI card presents a single question, designers and developers can ask about their target product, system or interface and a real-world example of that question in practice to act as an inspiration to help designers see potential applications of the card. Designers are required to use the information presented on the card to make their own inferences about their products and their end-users needs, with no pre-existing boundaries set in place. A key advantage of the

Table 1 Lenses and themes presented within the DwI framework

\begin{tabular}{|c|c|c|}
\hline Lens & Theme & Example card \\
\hline Architectural lens & $\begin{array}{l}\text { Draws primarily on ideas within architecture and urban planning, seeking to apply ideas } \\
\text { from the built environment } \\
\text { Concerns the structure and layout of items and behaviour }\end{array}$ & $\begin{array}{l}\text { Angles } \\
\text { Pave the Cowpaths }\end{array}$ \\
\hline Errorproofing lens & $\begin{array}{l}\text { Considers any behaviour that deviates from a target behaviour as an error and seeks to } \\
\text { reduce the likelihood of errors occurring. Seeks to design a system whereby these errors } \\
\text { cannot occur }\end{array}$ & $\begin{array}{l}\text { Are you sure? } \\
\text { Matched Affordances }\end{array}$ \\
\hline Interaction lens & $\begin{array}{l}\text { Fundamentally about users' interaction with the devices or displays. Based on the feedback } \\
\text { and feedforward of information between the user and the device being considered }\end{array}$ & $\begin{array}{l}\text { Kairos } \\
\text { Real-time feedback }\end{array}$ \\
\hline Ludic lens & $\begin{array}{l}\text { Focus on the potential for gamification of a device. Popularized by the view that playful } \\
\text { interactions can encourage the maintenance of behaviour }\end{array}$ & $\begin{array}{l}\text { Scores } \\
\text { Storytelling }\end{array}$ \\
\hline Perceptual lens & $\begin{array}{l}\text { Seeks to utilize biases in human perceptual system, for example use of heuristics, to target } \\
\text { the design and development of objects }\end{array}$ & $\begin{array}{l}\text { Colour associations } \\
\text { Nakedness }\end{array}$ \\
\hline Cognitive lens & $\begin{array}{l}\text { Based on cognitive psychology and an understanding of how individuals make decisions. } \\
\text { Seeks to bias individuals to make a desired decision }\end{array}$ & $\begin{array}{l}\text { Provoke empathy } \\
\text { Commitment and consistency }\end{array}$ \\
\hline Machiavellian lens & $\begin{array}{l}\text { Seeks to control the behaviour of individuals, by utilizing an "Ends Justify the Means" } \\
\text { approach }\end{array}$ & $\begin{array}{l}\text { Functional obsolescence } \\
\text { I cut, you choose }\end{array}$ \\
\hline Security lens & $\begin{array}{l}\text { Seeks to prevent undesired behaviour through direct countermeasures. Seeks to directly } \\
\text { control behaviour }\end{array}$ & $\begin{array}{l}\text { Peervailence } \\
\text { Coercive atmospherics }\end{array}$ \\
\hline
\end{tabular}


DwI approach is that it is a simple approach which allows non-experts to design new products quickly and efficiently. As an example, whilst design approaches such as Design Sprint [33] take 5 days to complete, DwI takes a single session to produce usable and innovative designs [34].

Despite the freedom that DwI offers as a design tool, it could be argued that this approach lacks guidance on how to best structure ideas. Indeed, designers are never required to actively consider the fundamental requirements of the system or interface being developed nor consider end-users needs, subsequently meaning that it is not possible to validate the generated ideas without significant further testing. To address this shortfall, the researchers considered whether established human factors methods aimed at developing and mapping the requirements of systems could be of benefit to users of the DwI toolkit, or act as a way to validate the subsequent produced designs. One such approach, popular within academic literature, is cognitive work analysis (CWA) [35, 36].

\subsection{Cognitive Work Analysis}

Originally developed for use in the nuclear power industry [35], CWA is a structured framework for understanding complex socio-technical systems, systems in which people and technology are closely coupled [36]. CWA can act as a key tool when developing and designing innovative systems [37]. Fuel-efficient driving is a suitable task for this analysis as drivers must interact with in-built vehicle mechanical systems, other road users, and increasingly, in-vehicle technology, including driver assist technology, and since the release of Tesla Model S in 2014, fully automated driving systems. CWA seeks to map the constraints that structure the working system, allowing practitioners to understand what is required of the system as well as what is both possible and not possible within the confines of system operations. By focusing on the constraints that frame a system, the analysis seeks to understand and support user needs for improved efficiency and safety. Drawing upon foundations in ecological psychology, general systems thinking and adaptive control systems [38], CWA has developed into a domain agnostic and highly flexible method that can be used to understand a variety of disciplines and also explore the potential of future system developments. CWA is an ideal method for envisioning revolutionary design as it promotes a focus on the fundamental requirements of the system [39]. Due to related theoretical underpinnings, it is proposed within this paper that the insights gained from CWA can be extended by DwI in order to develop usable interfaces with which users directly interact. By combining the free flow idea generation of DwI with the constraint-based framework of CWA, designers are free to be creative within their designs, provided that the fundamental needs of the system are met. Tools to extend the
CWA approach are needed as no typical means of using the outputs of CWA within design processes currently exists [40].

Developing a complete CWA is an extensive and timeconsuming process, and is largely beyond the scope of the current paper, which is focused upon initial idea generation following use of the DwI toolkit. The complete CWA process comprises of five key phases, Work Domain Analysis, Control Task Analysis, Strategies Analysis, Social Organization and Cooperation Analysis and Worker Competencies Analysis [41, 42]. The key phase of the CWA referenced throughout the current paper is the Work Domain Analysis. The primary focus of the Work Domain Analysis is the development of an abstraction hierarchy. The abstraction hierarchy aims to map the proposed system on multiple conceptual levels, ranging from its reason for existing to the physical objects that the system is comprised of. Five conceptual levels are considered when developing an abstraction hierarchy. The uppermost level maps the systems "Functional Purpose(s)", the system's raison d'etre, or reason(s) to exist. Below this level, the system's "Values and Priorities" are presented. The "Values and Priorities" level maps metrics for measuring the system's success, how users and observers can know that their system is achieving the outlined "Functional Purpose(s)". The central level of the abstraction hierarchy is the "Purpose Related Functions". Within this level are functions linking the system's activity to the roles offered by each of its constituent components. The fourth level is "Object Related Processes". Within this level the input of each "Physical Object" within the system is considered in terms of what it contributes to wider system functioning. The final or foundation level of the abstraction hierarchy is the "Physical Objects" level, which documents all of the tangible objects of which the system is comprised. The generated abstraction hierarchy can be validated using an exhaustive means-ends analysis, following the why-whathow triad approach [42]. It is possible to nominate any item within the hierarchy and ask the question "what does this do?". By examining all connections in the layer immediately above the node, it is possible to answer the question "why does it do this?". When considering all connections in the layer immediately below, it must be possible to answer the question "how does it achieve this?". This validation process ensures that all connections are suitable. Once completed, the abstraction hierarchy actively maps out the system for designers. This stage is considered essential for development as it can be seen as laying the foundation for the system under investigation. The abstraction hierarchy identifies the constraints on workers behaviour based upon their physical context [43]. Regarding the focus of the current paper, this can be considered in terms of how the wider road environment, including both 
infrastructure and other road users, and the current vehicle context, including its technological capacities, influence the achievement of greater fuel efficiency.

CWA offers analysts a technology agnostic approach to consider a system, allowing for the consideration of both technology and human agents in the same analysis. This makes it an ideal approach for the consideration of novel technology as well as a tool to consider the constraints for a new interface in a previously established working environment. Despite these benefits, the final outcome of the CWA analysis is not a complete workable design of the envisaged system or interface. It is in this gap that this paper is focused, exploring the use of DwI to progress thinking towards initial mock-up designs, in preparation for further work empirically assessing the impact that such interfaces can have.

\subsection{Research Goal}

This paper will document the process of combining knowledge gained from a developed CWA documenting fuel-efficient driving with DwI in the design of in-vehicle interfaces. This is applied to two in-vehicle interface development case studies. This paper will focus on the application of knowledge gained from the CWA to act as theoretical underpinning for interfaces developed using the DwI toolkit to examine the extent to which these methods can complement one another.

\section{Method}

\subsection{Participants}

To develop the interfaces, two main workshop sessions were held. The first workshop was comprised of two female participants, aged 26 and 39 years $(M=32.5)$, and one male participant, aged 24 years. All participants possessed a background in human factors and driving research, but did not have an understanding of fuel efficiency. The second workshop was comprised of three participants, two male participants, aged 32 and 33 years $(M=32.5)$, and one female participant, aged 31 years. Two of the participants held substantive backgrounds in human factors research. The third participant had considerable experience in the development of information displays, primarily for use by rail passengers. All participants were recruited via opportunity sampling and the use of a recruitment mailing list. Two of the three participants in each of workshop held a full UK driving license and had extensive experience driving on the UK road network. Participants were required to provide full informed consent prior to the start of the study. Although these groups are small, especially in line with work suggesting that innovation is positively correlated with group size
[44], practicalities of the study and participant availability restricted the use of larger samples. As the focus of the current work is to examine whether CWA and DWI could be integrated, two workshops were deemed preferable to a single case study workshop. Besides, smaller group sizes were advantageous in allowing the research facilitator to better manage the workshops.

\subsection{Procedure}

The University of Southampton Ethics Committee gave full ethical approval for this study prior to the start of the workshops. Both workshops followed the same structure, but due to differences in participants' backgrounds, experience and the volume of discussion, timings varied between groups. Participants were initially introduced to the research program the overall aims of the session, and they received a brief introduction on the concept of eco-driving and they improving fuel efficiency when driving through the modification of driver behaviour. Following this introduction, participants were introduced to a previously completed CWA documenting fuel-efficient driving [45]. The previously completed CWA had mapped the potential constraints that would operate around an eco-driving interface, across multiple driver skill levels and driving scenarios, for example waiting at traffic lights and accelerating to higher speed. Participants had access to all elements of the completed CWA, including a large poster scale print of the abstraction hierarchy. Introduction to the project, eco-driving and familiarization with the CWA lasted approximately $45 \mathrm{~min}$. During both introduction and familiarization stages, participants were encouraged to ask questions to the research team about the wider topics of fuel efficiency and eco-driving as well as the CWA in order to encourage deeper consideration and understanding of the subject area.

Once participants had been familiarized with the project objectives and the previously completed CWA, they were presented with a single scenario. For Workshop 1, this scenario was waiting at traffic lights; for Workshop 2 the scenario considered was overtaking. A single specific scenario was chosen in order to better frame the workshops and make most use of the available time. Participants were asked, using the presented CWA, to design an interface that would help the driver to become more fuel-efficient during the presented scenario. Participants were asked to work through all 101 DwI cards [34] whilst considering the scenario and the CWA [45] to inspire suitable designs. Participants were informed that they were free to use any form of interaction display within their design, including head-down displays (HDDs), head-up displays (HUDs), auditory signals and haptic signals. For the design element of the workshop, participants were presented with A3 sheets of paper, post-it notes and a variety of different coloured pens and actively 
encouraged to think in a creative manner when developing the required interfaces. Participants were asked to exhaustively consider whether each DwI card could, or should, be incorporated into the designed interface. Participants were told that they could either modify their existing design, or develop a new design incorporating their previous ideas with those generated by the use of further DwI cards. When participants introduced an interface element based upon a DwI card, a member of the research team asked them to discuss why and how this card informed their progressing design. The research team made substantive notes throughout this time to aid future understanding of the design. A member of the research team was on hand throughout the workshops to answer any questions that arose, to moderate the session and to ensure that each participant was able to contribute ideas to the session. The research facilitator, however, did not attempt to influence the group designs in anyway, and did not impose their opinions on the groups' designs during the workshops. Following the development of the initial design, the groups were asked to review their designs and ideas to ensure that all members of the group were happy to progress. Approximately $60 \mathrm{~min}$ was given to the design stage of the session, but participants were not explicitly timed.
The final phase of the workshop focused on the use of the previous presented CWA [45] to review and redesign the developed interface as appropriate. Participants were asked to reflect on all of the previously completed stages of the CWA, and discuss how each of the key elements within their interface was informed by the CWA. Despite this section of the workshop being largely a reflective exercise and a linear discussion process within the groups, it did spark considerable deliberation and discussion, lasting approximately $45 \mathrm{~min}$. Participants were free to revisit their design and modify should they feel this was required. Following this stage, participants were offered the opportunity to reflect upon their use of the DwI cards and the overall workshop experience. Table 2 presents a summary of the different workshop phases and timings for clarity.

\section{Results and Discussion}

Two interface mock-ups were developed from the workshops, following participants' designs. The interfaces presented here are initial mock-ups and presentation of ideas, and are not currently deployed in vehicles or simulator for testing.

Table 2 Workshop summary

\begin{tabular}{|c|c|c|c|c|}
\hline Phase & Content & $\begin{array}{l}\text { Timings } \\
(\min )\end{array}$ & Input & Outcomes \\
\hline Introduction and consent & $\begin{array}{l}\text { Researcher outlined the current } \\
\text { study, presenting participants } \\
\text { with an information sheet and } \\
\text { consent form }\end{array}$ & 5 & & $\begin{array}{l}\text { Participants aware of study design and } \\
\text { requirements and are able to give } \\
\text { informed consent }\end{array}$ \\
\hline $\begin{array}{l}\text { Introduction to fuel efficiency } \\
\text { and familiarization with the } \\
\text { previously completed CWA }\end{array}$ & $\begin{array}{l}\text { Participants were presented } \\
\text { with an overview of fuel- } \\
\text { efficient driving, the behavioral } \\
\text { approaches to fuel usage and } \\
\text { familiarized with the com- } \\
\text { pleted CWA }\end{array}$ & 45 & $\begin{array}{l}\text { Previously Com- } \\
\text { pleted CWA [45] }\end{array}$ & $\begin{array}{l}\text { Participants knowledge grounded within } \\
\text { previously completed works and sys- } \\
\text { tem operations }\end{array}$ \\
\hline $\begin{array}{l}\text { Scenario presentation and inter- } \\
\text { face design using DwI cards }\end{array}$ & $\begin{array}{l}\text { Participants were presented } \\
\text { with a scenario and asked to } \\
\text { exhaustively use the DwI cards } \\
\text { to design a suitable in-vehicle } \\
\text { interface to support drivers in } \\
\text { completing the scenario as fuel } \\
\text { efficiently as possible }\end{array}$ & 60 & 101 DwI cards [34] & $\begin{array}{l}\text { Initial interface(s) developed prior to } \\
\text { further refinement }\end{array}$ \\
\hline $\begin{array}{l}\text { Review and redesign of the } \\
\text { developed interface using the } \\
\text { previously presented CWA }\end{array}$ & $\begin{array}{l}\text { Participants were asked to reflect } \\
\text { on their completed interface(s) } \\
\text { and discuss how each element } \\
\text { was informed by the previously } \\
\text { developed CWA. Elements } \\
\text { which could not be explained } \\
\text { using the previously developed } \\
\text { CWA were refined or removed }\end{array}$ & 45 & $\begin{array}{l}\text { Initial interface } \\
\text { design and the pre- } \\
\text { viously completed } \\
\text { CWA [45] }\end{array}$ & Final developed interface(s) \\
\hline Reflection & $\begin{array}{l}\text { Participants were asked to reflect } \\
\text { on their use of CWA, the DwI } \\
\text { cards and the workshop experi- } \\
\text { ence }\end{array}$ & 5 & & $\begin{array}{l}\text { Knowledge of participants experience } \\
\text { using the methodology }\end{array}$ \\
\hline
\end{tabular}




\subsection{Workshop 1: Waiting at Traffic Lights}

The interface mock-up designed for the task of "Waiting at Traffic Lights" is presented within Fig. 1. This scenario was chosen as it is a point in the drive where the driver is able to review their current performance

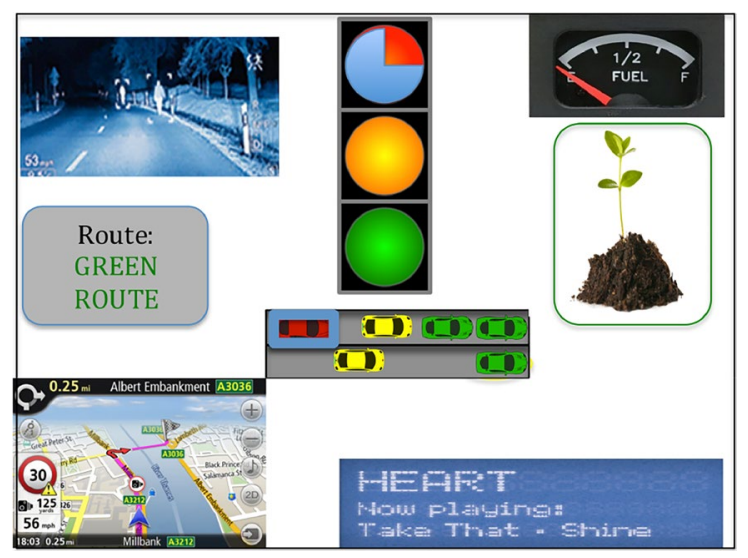

Fig. 1 Designed HDD interface mock-up for the scenario "Waiting at Traffic Lights" without becoming distracted from the overall driving task and risking their safety. The interface devised was based on 47 unique DwI cards, across all eight lenses. It should be noted that the interface was designed for future use, as it does account for the potential of interconnected vehicles and infrastructure, a potential explicitly presented within the CWA that participants used to guide their design.

The developed interface contains eight key elements, a countdown traffic light display, a potential to proceed display, a surround vision system, a fuel efficiency feedback display, a minimized satellite navigation display, a route selection display, a fuel gauge and a radio/entertainment display. A summary of each interface element and the role each element fulfils is provided in Table 3.

Each element within the interface was developed using the combined DwI and CWA approach as outlined previously. To provide an illustration of the use of the DwI cards, Table 4 provides a summary of the different DwI cards that inspired the design of the fuel efficiency feedback display. Also included within this table is the use of cards that were seen as generic and an inspiration for the wider display rather than any single element.

Table 3 Summary of interface elements

\begin{tabular}{|c|c|c|}
\hline Element & Element name & Element explanation \\
\hline 1 & Count down traffic light display & $\begin{array}{l}\text { Display indicating to drivers the approximate time the traffic lights will remain on their current } \\
\text { colour, allowing drivers to gauge relative wait time. In the current example, the lights are on } \\
\text { red and have approximately a quarter of the time remaining }\end{array}$ \\
\hline 2 & Potential to proceed display & $\begin{array}{l}\text { Display indicating the likeliness a driver is to proceed through the next revolution of lights } \\
\text { Green coloured cars indicate that the vehicle will proceed, yellow indicating it is possible the } \\
\text { vehicle will proceed through the lights should the vehicles preceding it react to the changing } \\
\text { traffic lights in a positive manner and red indicating that the vehicle is highly unlikely to pass } \\
\text { through on the current revolution of the lights } \\
\text { The driver's vehicle is indicated by larger selection box. In the current example, this display is } \\
\text { indicating that the driver is unlikely to proceed through the next revolution of traffic lights }\end{array}$ \\
\hline 3 & Surround vision system & $\begin{array}{l}\text { Opportunity to provide drivers with a view of events happening to the sides and rear of the } \\
\text { vehicle to increase the chance of detecting pedestrians who may be about to cross the road } \\
\text { regardless of the indication on the traffic lights }\end{array}$ \\
\hline 4 & Fuel efficiency feedback display & $\begin{array}{l}\text { The fuel efficiency presents a pictorial representation of the driver's current fuel efficiency } \\
\text { based on their ability to follow eco-driving principles, such as gentle acceleration and brak- } \\
\text { ing. It is currently envisioned that this display will be customizable by the user to account for } \\
\text { environmental motivations, using images of a growing tree, such as in the current example, } \\
\text { or images of coins for individuals who are financially motivated }\end{array}$ \\
\hline 5 & Minimized satellite navigation display & $\begin{array}{l}\text { Display drivers' current road position and allow drivers to potentially modify their route or } \\
\text { destination whilst the vehicle is stationary }\end{array}$ \\
\hline 6 & Route selection display & $\begin{array}{l}\text { Opportunity for drivers to select a route based on fuel efficiency. Within the current example } \\
\text { the driver has selected the most fuel-efficient "Green" route }\end{array}$ \\
\hline 7 & Fuel gauge & $\begin{array}{l}\text { The fuel gauge presents the vehicle's current remaining fuel level. It is advised that the driver } \\
\text { in the example refuels soon }\end{array}$ \\
\hline 8 & Radio/entertainment display & $\begin{array}{l}\text { The interface also displays the driver's current entertainment system information, as available } \\
\text { on traditional in-vehicle entertainment displays. As the vehicle is stationary within the given } \\
\text { scenario it is possible to interact with the entrainment system with minimal safety implica- } \\
\text { tions }\end{array}$ \\
\hline
\end{tabular}


Table 4 DwI cards used to inspire design of the fuel efficiency display within the "Waiting at Traffic Lights" interface

\begin{tabular}{|c|c|c|}
\hline Lens & Card & Description/reasoning \\
\hline Architectural & Converging and diverging & Offer a fuel efficiency score to encourage engagement with the task of becoming fuel-efficient \\
\hline Architectural & Positioning & Only activate key sections of the display when stationary \\
\hline Architectural & Segmentation and spacing & $\begin{array}{l}\text { Divide the interface display into individual elements so that individuals can interact with indi- } \\
\text { vidual elements }\end{array}$ \\
\hline Architectural & Simplicity & Use of pictorial representations wherever possible to encourage a simple and accessible display \\
\hline Error proofing & Defaults & $\begin{array}{l}\text { Default the display options to be the most fuel-efficient possible and focus on environmental } \\
\text { rather than monetary gains from the system }\end{array}$ \\
\hline Error proofing & Portions & $\begin{array}{l}\text { Divide the interface into smaller elements and offer users different feedback for different } \\
\text { achievements and actions. }\end{array}$ \\
\hline Interaction & Kairos & Switch to a traffic light information display as the vehicle approaches the traffic light \\
\hline Interaction & Partial completion & $\begin{array}{l}\text { Show users their achievements so far, how much fuel they have saved in the current journey by } \\
\text { being fuel-efficient }\end{array}$ \\
\hline Interaction & Progress bar & $\begin{array}{l}\text { Digital display/pictorial representation of a plant or pile of coins acts as a progress bar towards } \\
\text { overall fuel efficiency goal }\end{array}$ \\
\hline Interaction & Real-time feedback & $\begin{array}{l}\text { Digital display/pictorial representation of a plant or pile of coins acts as real-time feedback to } \\
\text { fuel usage and potential emissions }\end{array}$ \\
\hline Interaction & Summary feedback & Give information about current performance via pictorial representation \\
\hline Interaction & Tailoring & $\begin{array}{l}\text { Offer option to change plant representation to financial information represented by a pile of } \\
\text { coins. }\end{array}$ \\
\hline Ludic & Challenges and targets & $\begin{array}{l}\text { Allow users to set their own personalized fuel efficiency goals to reach in order to gain achieve- } \\
\text { ments }\end{array}$ \\
\hline Ludic & Collections & Allow permanent collection of achieved goals/add the option to grow a permanent "garden" \\
\hline Ludic & Levels & $\begin{array}{l}\text { Achieve rewards at staggered levels of achievement on the pictorial representations to encourage } \\
\text { greater engagement with the task of fuel-efficient driving as the journey continues }\end{array}$ \\
\hline Ludic & Rewards & Potential to gain visual rewards and permanent achievements based on actions \\
\hline Ludic & Scores & $\begin{array}{l}\text { Give comparative behaviour feedback to encourage future behaviour, so that a driver must } \\
\text { improve their fuel efficiency in order to gain the same level of reward }\end{array}$ \\
\hline Perceptual & Metaphors & Use of pictorial representation to make fuel saving more apparent to the driver \\
\hline Cognitive & Assuaging guilt & Visual representation of a plant growing to encourage guilt reduction \\
\hline Cognitive & Commitment and consistency & $\begin{array}{l}\text { Encourage users to buy into the overall idea of reducing carbon footprint by incorporating envi- } \\
\text { ronmental or financial ideas into the display }\end{array}$ \\
\hline Cognitive & Emotional engagement & $\begin{array}{l}\text { Encourage users to engage with the idea that fuel saving is the correct thing to do for both the } \\
\text { environment and their financial wellbeing }\end{array}$ \\
\hline Cognitive & Habits & $\begin{array}{l}\text { No significant changes in driver's current actions are required. The interface acts as an informa- } \\
\text { tion prompt }\end{array}$ \\
\hline Cognitive & Rephrasing and renaming & Potential to reframe eco-driving and emissions saving to a direct financial saving \\
\hline Machiavellian & Bundling & $\begin{array}{l}\text { Pairing fuel saving or financial saving with emission reduction so that in order to save money the } \\
\text { user consequently reduces emissions }\end{array}$ \\
\hline Machiavellian & Worry resolution & $\begin{array}{l}\text { Reduce worry caused by anti-environmental action of driving by displaying positive environ- } \\
\text { mental images when driver is fuel-efficient }\end{array}$ \\
\hline
\end{tabular}

\subsubsection{Validation of the Display}

In order to ensure that the display adhered to the previously completed CWA [45], each element of the interface was compared against this documentation. Due to its focus in mapping the physical objects that comprise a system as well as the overall aims and objectives of the system, the abstraction hierarchy created as part of the work domain analysis component was seen as the primary validation tool.

When considering the abstraction hierarchy and taking the example of the fuel efficiency display (Item 4, Table 3), this item can be linked to the functional purposes of "Save Energy" and "Reduce Emissions", holding the values and priorities of "Optimize Vehicle Range", "Reduce Fuel Usage", "Optimize Driver Satisfaction", "Reduce $\mathrm{NO}_{x}$ " and "Reduce $\mathrm{CO}_{2}$ ". It does this by accounting for and providing drivers more information regarding the purpose-related function "Control Vehicle Motion". To calculate the relative success of the driver and be able to contribute feedback, the display is able to present information to the driver related to their ability to "Control Acceleration" and "Control Vehicle Speed", have knowledge of the "Speed Limit" and encourage "Smooth 
Motion". In order to achieve these goals, the device can take information from the vehicle, as captured within the physical objects including "Clutch", "Fuel", "Brake Pedal" and "Accelerator Pedal". In addition, this application is reliant of the physical object "V2X Communication" to allow it to accurately communicate with surrounding infrastructure to allow presentation of the lights duration and offer an estimation of approximate dwell time. The corresponding nodes from the abstraction hierarchy are presented in Fig. 2, mapping how this display element can be used to reduce emissions.

A similar validation process was undertaken for all interface elements in order to ensure that the functioning of each element was warranted based upon the previously generated specifications. Using the generated CWA as a validation tool helps to ensure that each interface element can contribute to the primary function of the system. In this way the developed interface can be seen to support users in achieving greater fuel efficiency. Of note is that this interface display makes use of both feedback systems, as shown by fuel efficiency feedback display (Table 3, Item 4), but also feedforward information, provided by the count down traffic light display (Table 3, Item 1) and potential to proceed display (Table 3, Item 2). By providing feedback on behaviour, it is hoped that long-term drivers develop positive driving habits. By providing feedforward information, drivers will be aware of both the time they have to wait, removing any need for anticipatory actions, and the likelihood of passing through the lights, allowing for more gentle acceleration within the traffic flow if they would be required to again wait at the lights.

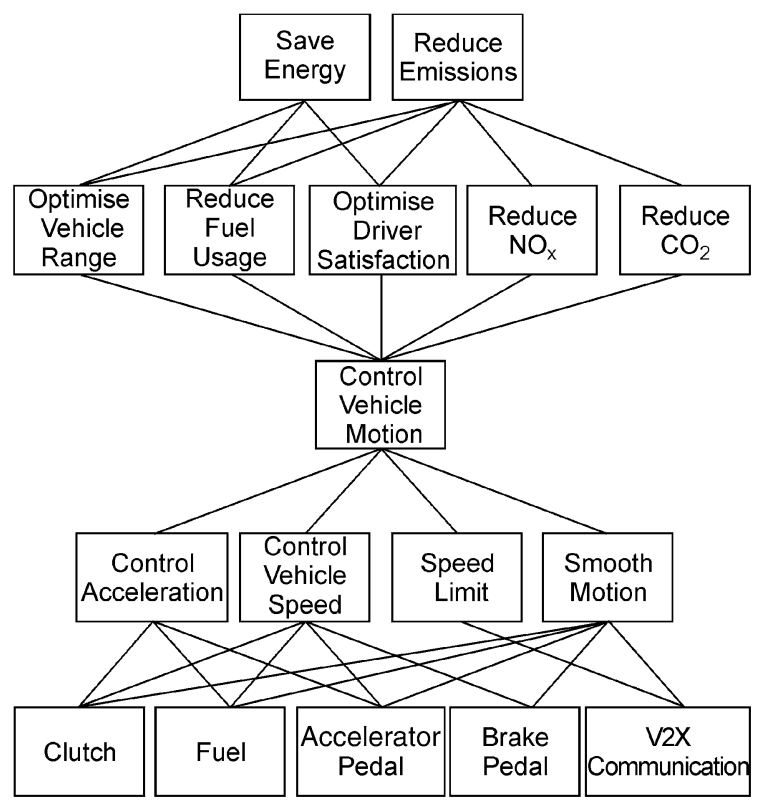

Fig. 2 Subset of the abstraction hierarchy accounted for by the fuel efficiency display (Item 4, Table 3)

\subsection{Workshop 2: Accelerating to Overtake}

The interface designed for the task of "Accelerating to Overtake" is presented within Figs. 3 and 4. This scenario of overtaking is not associated with the typical activity of fuel-efficient driving; however, it is an activity that many drivers are likely to engage in on a regular basis. The devised interface was based on 29 unique DwI cards and, similar to the previous "Waiting at Traffic Lights" interface, utilized all eight lenses. Unlike the previous interface display, which only used the vehicle's HDD, the overtaking interface is primarily presented as part of the vehicle's HUD (Fig. 3) in order to remove the need for the driver to divert their gaze away

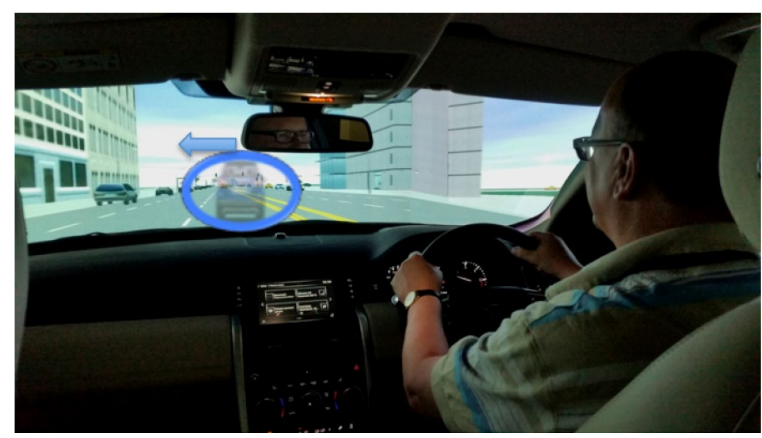

Fig. 3 Designed HUD interface mock-up for the scenario "Accelerating to Overtake"

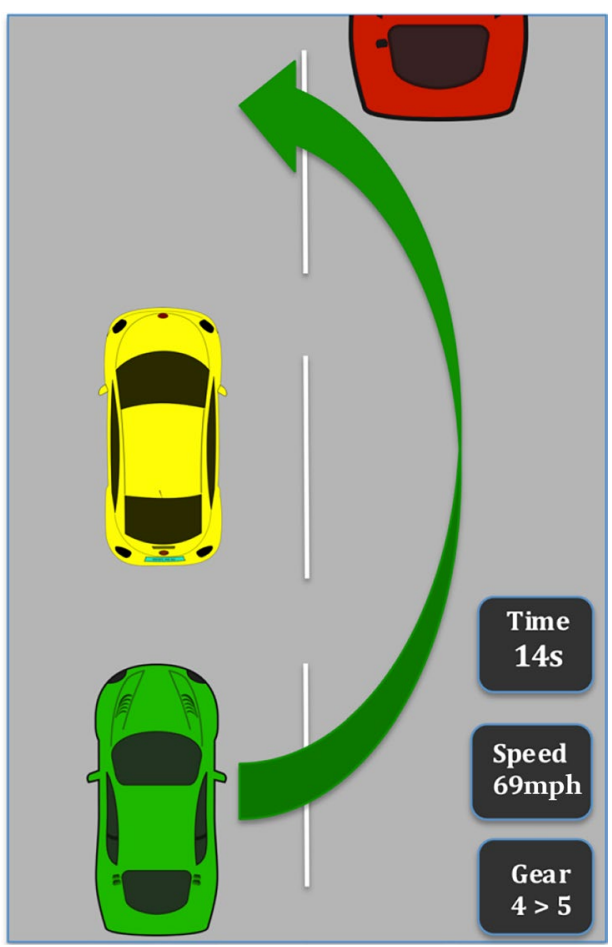

Fig. 4 Designed HDD interface mock-up for the scenario "Accelerating to Overtake" 
from the road ahead. This information can be supplemented with auditory feedforward information presented to the driver prior to the start of the manoeuvre. A breakdown of the task and the details of the actions that will be undertaken, supporting this auditory feedforward information, are presented in the vehicle's HDD for redundancy, as shown in Fig. 4.

Within the current image, the vehicle has overtaken the vehicle in the middle lane and is being informed they should be prepared to follow the ghost car in moving back to the middle lane.

Within the HDD interface, the driver presented in the rear green car, is being informed that in $14 \mathrm{~s}$ it will be safe to overtake the preceding yellow car, and is informed that the optimal overtaking speed is $69 \mathrm{mph}$ in 5 th Gear.
When considering the "Accelerating to Overtake" HUD display (Fig. 3), the key novel feature is the presentation of the ghost car. The ghost car presents users with an ideal model of how to complete the task of overtaking, offering guidance on timing and speed, constrained with the view of completing the manoeuvre in the most fuel-efficient way possible. This idea has been heavily influenced by the use of ghost cars that are popular in gaming. The HDD display, in contrast, is not designed to present any novel information to the driver, but rather reinforce information that the driver may have missed from the audio system, including time until manoeuvre and the ideal speed the car should travel in order to complete the manoeuvre and remain fuel-efficient. Table 5 provides a summary of the

Table 5 DwI cards used to inspire design of the "Accelerating to Overtake" interface

\begin{tabular}{|c|c|c|}
\hline Lens & Card & Description/reasoning \\
\hline Architecture & Converging and diverging & Channel people into different lanes so they safely split up and allow room for efficient overtaking \\
\hline Architecture & Conveyor belts & Overtaking interface only appears following request-button press or similar interaction \\
\hline Architecture & Mazes & $\begin{array}{l}\text { Encourage following of the most fuel-efficient path when overtaking to still achieve goal but in a } \\
\text { fuel-efficient way }\end{array}$ \\
\hline Architecture & Positioning & Only allow access to the application when appropriate and safe \\
\hline Architecture & Roadblock & Adjust the speed or limit speed of the car by use of a ghost car \\
\hline Architecture & Simplicity & Design with simplicity and use of HUD rather than HDD \\
\hline Error proofing & Are you sure? & Ghost car only appears as car starts manoeuvre and/or is requested \\
\hline Error proofing & Choice editing & Only present the desired route and ghost car information to remove the potential for choice. \\
\hline Error proofing & Defaults & Limit available guidance to be the best for the current road situation. \\
\hline Error proofing & Did you mean? & Visual indication to driver if they are not at the ideal speed for current road situation \\
\hline Interaction & Kairos & Inform users the best moment to make an overtaking manoeuvre. \\
\hline Interaction & Progress bar & Show on HUD progress compared to a ghost car. \\
\hline Interaction & Tunnelling and wizards & Ghost car acts as a wizard to guide users \\
\hline Ludic & Challenges and targets & User is challenged to match as closely as possible to ghost car to achieve greatest fuel efficiency \\
\hline Perceptual & (A)Symmetry & Match HUD and change actions to show clear link \\
\hline Perceptual & Colour association & $\begin{array}{l}\text { Colour changes on car in interface for when car considering an overtaking manoeuvre } \\
\operatorname{Red}=\mathrm{Bad} / \text { Not now, Green }=\text { Good/Go now }\end{array}$ \\
\hline Perceptual & Contrast & $\begin{array}{l}\text { Flashing box on the display surrounding car to stress good speed or RPM required to complete } \\
\text { the manoeuvre in a fuel-efficient way }\end{array}$ \\
\hline Perceptual & Implied sequences & Ghost car changes and progresses in manoeuver following driver actions \\
\hline Perceptual & Mood & Use of Green $=$ Good to encourage link between actions and environmental impact \\
\hline Perceptual & Perceived affordances & Overtaking lines and guidance only appears when it is safe to perform an overtaking action. \\
\hline Perceptual & Prominence & Use of HUD display to make ghost car salient and obvious to the driver \\
\hline Perceptual & Seductive atmospherics & Use of ambient sounds to match vehicles RPM and make eco-driving more immediate to driver \\
\hline Cognitive & Commitment and consistency & $\begin{array}{l}\text { Commit users to the idea that eco-driving does not relate to a slow or frustrating journey. And be } \\
\text { consistent in display and information provision to help easier buy-in }\end{array}$ \\
\hline Cognitive & Expert choice & Ghost car acts as an expert "user" to suggest the best action to take in the current situation \\
\hline Cognitive & Habits & $\begin{array}{l}\text { Make it easy for people to use the system and make use of the overtaking application so that it } \\
\text { becomes ingrained into actions }\end{array}$ \\
\hline Machiavellian & Forced dichotomy & $\begin{array}{l}\text { No middle ground available in the system, only expert choices are presented when the system is } \\
\text { activated }\end{array}$ \\
\hline Machiavellian & Format lock-in & $\begin{array}{l}\text { Eco-based system is the only option, if users want overtaking advice they see the most fuel- } \\
\text { efficient way of achieving this goal }\end{array}$ \\
\hline Machiavellian & Serving suggestions & Display ideal speed and RPM to the driver before starting the overtaking manoeuvre \\
\hline Security & Where you are & Disable the option for the overtaking app to work on roads where overtaking is not an option \\
\hline
\end{tabular}




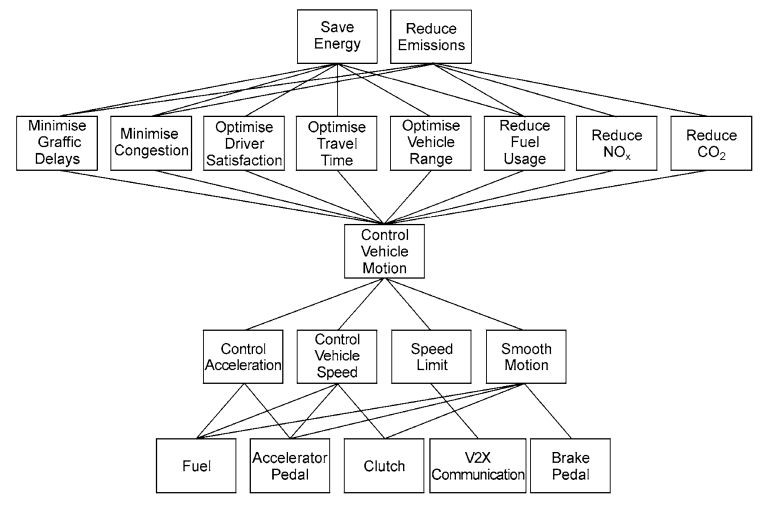

Fig. 5 Subset of the abstraction hierarchy accounted for by the "Accelerating to Overtake" display

use of different DwI cards that inspired design of the fuel efficiency feedback display, it includes both HUD and HDD elements.

\subsubsection{Validation of the Display}

Similar to the "Waiting at Traffic Lights" interface, the "Accelerating to Overtake" interface was compared to the CWA abstraction hierarchy, and appropriate elements were identified as shown in Fig. 5. To ensure that the interface fulfilled functional purposes of "Save Energy" and "Reduce Emissions $\left(\mathrm{CO}_{2}\right.$ and $\left.\mathrm{NO}_{x}\right)$ ". Within this interface these goals are achieved as they adhere to the values and priorities of "Minimize Traffic Delay", "Minimize Congestion", "Optimize Driver Satisfaction" and "Optimize Travel Time". Whilst overtaking is generally not considered fuel-efficient, due to the additional fuel required to accelerate the vehicle, overtaking may "Optimize Vehicle Range" and "Reduce Fuel Usage" if the driver is able to shift to a higher gear. Assuming a form of combustion engine, these engines are more efficient at higher gears, potentially allowing the values and priorities of "Reduce $\mathrm{NO}_{x}$ " and "Reduce $\mathrm{CO}_{2}$ " to be achieved. The system achieves these goals by accounting for and providing drivers more information regarding the purpose-related function "Control Vehicle Motion". To calculate the relative success of the driver and be able to provide feedforward information to the driver, the display presents information to the driver related to their ability to "Control Acceleration" and "Control Vehicle Speed", have knowledge of the "Speed Limit" and encourages "Smooth Motion". In order to achieve these goals, the device can take information from the vehicle, as captured within the physical objects including "Clutch", "Fuel", "Brake Pedal" and "Accelerator Pedal". In addition, this application is reliant of the physical object "V2X Communication" to allow the vehicle to accurately communicate with nearby vehicles and infrastructure to allow accurate estimation of the moment the driver can safely overtake.

\section{General Discussion}

The aim of this paper was to present initial work examining use of CWA [35] to constrain interfaces developed using DwI [25] to encourage fuel-efficient driving. By focusing on user requirements, as provided by CWA [45], it was seen that the discussions related to the DwI cards were highly structured and directed. By providing the CWA and DwI cards, individuals without a background in design or fuel-efficient driving were able to develop initial mock-ups of potential interfaces. Previous research [40] has highlighted the need to extend the insights offered by CWA and the present investigation suggests that DwI is an appropriate tool for this goal.

DwI was envisioned as a "suggestion tool" [25] to inspire novel designs. Within the current study DwI was used to develop interfaces that aim to reduce fuel use and emissions whilst driving to limit the negative impact such emissions can have, both on human respiratory health $[3,4]$ and the wider eco-system [5, 6]. Although neither interface directly interacted with the driver or the vehicular controls, the presence of such interfaces may be sufficient to encourage greater fuel efficiency as the drivers become more aware of their overall fuel use [19]. By actively promoting fuel efficiency within everyday driving, drivers can become aware of the impact that their behaviour can have and consequently take steps to reduce both their fuel usage and corresponding emissions [45].

CWA seeks to exhaustively map a domain in order to facilitate extensive understanding and allow informed decisions to be made in response to system redevelopment [35]. However, CWA lacks a clear avenue for progressing insights into workable interfaces. In contrast, DwI [25] is a toolkit to aid novel design, but lacks any true grounding to ensure that the designs developed meet user needs and requirements. Within the current paper, it is argued that CWA can be used to inform, guide and constrain the generated interfaces developed using DwI. In turn, it was found that CWA could be used to validate the proposed interfaces developed using DwI, ensuring that the DwI cards were able to actively address the fundamental requirements of the system under investigation. Although this paper only provides a case study combining the methods, it is hoped that future research can develop a formalized approach to provide best practice guidance on using both CWA and DwI to develop human-system interfaces. As previous research suggests that no typical means of using the outputs of CWA within design currently exist [40], the current paper provides a clear avenue regarding progressing this methodology towards interface design. 
It is clear that the interface mock-ups presented in Figs. 1, 3 and 4 are not ready for immediate deployment in a vehicle or simulator testing facility and require further work in order to make sure they are aesthetically pleasing. This research has not directly considered the importance of aesthetics in interface design and development, and the created interface mock-ups would benefit from input from a designer to improve visual appeal. Provided that all features of the display are maintained, developers can be sure that the interface fulfils user needs and requirements for the goal of minimizing fuel consumption. Therefore, it is important that the combination of CWA and DwI happens early in an interface development cycle. Extending this point, initial interface design is but the first step in the design journey [46]. Testing is required, both in laboratory and field studies, to fully appreciate end users' engagement in the displays.

It should be noted that a limitation of the current paper is that participants were only presented with the combined CWA and DwI cards, so it is not possible to assess the direct influence that either of these elements held over the final designs, or indeed whether the designs generated within the research would be substantially different were they developed by a different team which lacked these resources. This research was intended to look at the potential for the combination of the CWA and DwI approaches and considerable more work is required to elucidate the relative value in this approach.

Future research is needed to examine the extent to which a constrained DwI approach can develop novel ideas for deployment in vehicles. It would also be useful to present the developed ideas to a variety of external potential end users in order to gain feedback and provide practical validation beyond that gathered from the theoretical validation offered by CWA. This further validation will enable researchers to identify ideas worthy of further pursuit, including the potential to explore the impact of both interfaces within an empirical and user-focused simulator study, whereby fuel savings and overall interface effectiveness can be directly assessed.

\section{Conclusions}

This paper presents a proof of concept that the open and domain agnostic toolkit, Design with Intent, could be constrained and used to develop interfaces when supported by the human factors method, Cognitive Work Analysis. Participants, individuals without a background in fuel-efficient driving or design, were able to take the insights gained from the CWA process and confidently work through the DwI toolkit to develop potential interfaces. It can be argued that the DwI toolkit allowed participants to create initial concepts, whilst CWA acted to constrain the ideas to ensure that they remained focused on the end goals of the system. This study acts as a proof of concept in which combining these two distinct methodologies is possible and, more importantly, it offers a potentially valuable approach when developing interface concepts that are grounded within design principles.

Acknowledgements This work was funded by the UK Engineering and Physical Sciences Research Council (EPSRC) Grant EP/N022262/1 "Green Adaptive Control for Future Interconnected Vehicles" (www.gactive.uk). The authors would like to offer thanks to all participants who gave their time to participate within the design workshop presented within the current work. The authors would like to thank Daniel Fay (University of Southampton) for his assistance in developing the abstraction hierarchy figures within this manuscript.

\section{Compliance with Ethical Standards}

Conflict of interest On behalf of all the authors, the corresponding author states that there is no conflict of interest.

Open Access This article is licensed under a Creative Commons Attribution 4.0 International License, which permits use, sharing, adaptation, distribution and reproduction in any medium or format, as long as you give appropriate credit to the original author(s) and the source, provide a link to the Creative Commons licence, and indicate if changes were made. The images or other third party material in this article are included in the article's Creative Commons licence, unless indicated otherwise in a credit line to the material. If material is not included in the article's Creative Commons licence and your intended use is not permitted by statutory regulation or exceeds the permitted use, you will need to obtain permission directly from the copyright holder. To view a copy of this licence, visit http://creativecommons.org/licenses/by/4.0/.

\section{References}

1. Department for Environment Food and Rural Affairs: Causes of air pollution. UK AIR Air Information Resource. https://uk-air. defra.gov.uk/air-pollution/causes (2017). Accessed 24 Apr 2019

2. Hill, N., Brannigan, C., Smokers, R., et al.: EU Transport GHG: Routes to $2050 \mathrm{II}-$ final project report funded by the European Commission's Directorate-General Climate Action, Brussels (2012)

3. McCubbin, D.R., Delucchi, M.A.: The health costs of motorvehicle-related air pollution. J. Transp. Econ. Policy 33, 253-286 (1999)

4. Buckeridge, D.L., Glazier, R., Harvey, B.J., et al.: Effect of motor vehicle emissions on respiratory health in an urban area. Environ. Health Perspect. 110(3), 293-300 (2002)

5. Karl, T.R., Trenberth, K.E.: Modern global climate change. Science 302(5651), 1719-1723 (2003)

6. Chapman, L.: Transport and climate change: a review. J. Transp. Geogr. 15(5), 354-367 (2007)

7. Li, L., Gong, Y., Deng, J., et al.: $\mathrm{CO} 2$ reduction request and future high-efficiency zero-emission argon power cycle engine. Automot. Innov. 1(1), 43-53 (2018)

8. Allison, C.K., Stanton, N.A.: Eco-driving: the role of feedback in reducing emissions from everyday driving behaviours. Theor. Issues Ergon. Sci. 20(2), 85-104 (2019)

9. Chan, C.C.: The state of the art of electric, hybrid, and fuel cell vehicles. Proc. IEEE 95(4), 704-718 (2007) 
10. Barth, M., Boriboonsomsin, K.: Energy and emissions impacts of a freeway-based dynamic eco-driving system. Transp. Res. Part D: Transp. Environ. 14(6), 400-410 (2009)

11. Barkenbus, J.N.: Eco-driving: an overlooked climate change initiative. Energy Policy 38(2), 762-769 (2010)

12. Stillwater, T., Kurani, K.S.: Drivers discuss ecodriving feedback: goal setting, framing, and anchoring motivate new behaviors. Transp. Res. Part F: Traffic Psychol. Behav. 19, 85-96 (2013)

13. Martin, E., Chan, N., Shaheen, S.: How public education on ecodriving can reduce both fuel use and greenhouse gas emissions. Transp. Res. Record: J. Transp. Res. Board 2287(1), 163-173 (2012)

14. Lockton, D., Harrison, D. J., Stanton, N. A.: Choice architecture and design with intent. In: Wong, B.L.W., Stanton, N.A. (eds.) Proceedings of the 9th Bi-annual International Conference on Naturalistic Decision Making, Swindon (2009)

15. McIlroy, R.C., Stanton, N.A., Harvey, C.: Getting drivers to do the right thing: a review of the potential for safely reducing energy consumption through design. IET Intell. Transp. Syst. 8(4), 388-397 (2013)

16. Jain, R.K., Taylor, J.E., Peschiera, G.: Assessing eco-feedback interface usage and design to drive energy efficiency in buildings. Energy Build. 48, 8-17 (2012)

17. Jamson, A.H., Hibberd, D.L., Merat, N.: Interface design considerations for an in-vehicle eco-driving assistance system. Transp. Res. Part C Emerg. Technol. 58, 642-656 (2015)

18. Attari, S.Z., DeKay, M.L., Davidson, C.I., et al.: Public perceptions of energy consumption and savings. Proc. Natl. Acad. Sci. 107(37), 16054-16059 (2010)

19. Abrahamse, W., Steg, L., Vlek, C., et al.: The effect of tailored information, goal setting, and tailored feedback on household energy use, energy-related behaviors, and behavioral antecedents. J. Environ. Psychol. 27(4), 265-276 (2007)

20. Andrieu, C., Saint Pierre, G.: Comparing effects of eco-driving training and simple advices on driving behavior. Procedia Soc. Behav. Sci. 54, 211-220 (2012)

21. Tulusan, J., Staake, T., Fleisch, E.: Providing eco-driving feedback to corporate car drivers: what impact does a smartphone application have on their fuel efficiency? In: Proceedings of the 2012 ACM Conference on Ubiquitous Computing, ACM, Pittsburgh, September 2012

22. Mensing, F., Bideaux, E., Trigui, R., et al.: Eco-driving: an economic or ecologic driving style? Transp. Res. Part C Emerg. Technol. 38, 110-121 (2014)

23. Simon, H.A.: The Sciences of the Artificial. MIT Press, Cambridge (1969)

24. Redström, J.: Towards user design? On the shift from object to user as the subject of design. Des. Stud. 27(2), 123-139 (2006)

25. Lockton, D., Harrison, D., Stanton, N.A.: The design with intent method: a design tool for influencing user behaviour. Appl. Ergon. 41(3), 382-392 (2010)

26. Hatcher, G., Ion, W., Maclachlan, R., et al.: Evolving improvised ideation from humour constructs: a new method for collaborative divergence. Creat. Innov. Manag. 27(1), 91-101 (2018)
27. Schweitzer, F., Gassmann, O., Rau, C.: Lessons from ideation: where does user involvement lead us? Creat. Innov. Manag. 23(2), 155-167 (2014)

28. Barker, R.G.: Ecological Psychology: Concepts and Methods for Studying the Environment of Human Behavior. Stanford University Press, Stanford (1968)

29. Gibson, J.J.: The Ecological Approach to Visual Perception. Erlbaum, Hillsdale (1986)

30. Norman, D.A.: Affordance, conventions, and design. Interactions 6(3), 38-43 (1999)

31. McGrenere, J., Ho, W.: Affordances: clarifying and evolving a concept. In: Proceedings of Graphics Interface 2000, Canadian Human-Computer Communications Society, Montréal, 15-17 May 2000

32. Buchanan, R.: Declaration by design: rhetoric, argument, and demonstration in design practice. Des. Issues 2, 4-22 (1985)

33. Banfield, R., Lombardo, C.T., Wax, T.: Design Sprint: A Practical Guidebook for Building Great Digital Products. O’Reilly Media, Sebastopol (2015)

34. Lockton, D.: Design with Intent: 101 Patterns for Influencing Behaviour Through Design. Equifine, Madison (2010)

35. Rasmussen, J.: Information Processing and Human-Machine Interaction. An Approach to Cognitive Engineering. Elsevier Science, New York (1986)

36. Stanton, N.A., Salmon, P.M., Walker, G.H., et al.: Cognitive Work Analysis Applications, Extensions and Future Directions. CRC Press, Boca Raton (2018)

37. Rasmussen, J.: The role of error in organizing behaviour. Ergonomics 33(10-11), 1185-1199 (1990)

38. Fidel, R., Pejtersen, A.M.: From information behaviour research to the design of information systems: the cognitive work analysis framework. Inf. Res: Int. Electron. J. 10(1), paper 210 (2004)

39. Naikar, N., Lintern, G.: A review of "cognitive work analysis: towards safe, productive, and healthy computer-based work" by Kim J. Vicente. Int. J. Aviat. Psychol. 12(4), 391-400 (2002)

40. Read, G.J., Salmon, P.M., Lenné, M.G.: Cognitive work analysis and design: current practice and future practitioner requirements. Theor. Issues Ergon. Sci. 16(2), 154-173 (2015)

41. Vicente, K.J.: Cognitive Work Analysis: Towards Safe, Productive, and Healthy Computer-Based Work. CRC Press, Mahweh (1999)

42. McIlroy, R.C., Stanton, N.A.: Getting past first base: going all the way with cognitive work analysis. Appl. Ergon. 42(2), 358-370 (2011)

43. Naikar, N.: Beyond interface design: further applications of cognitive work analysis. Int. J. Ind. Ergon. 36(5), 423-438 (2006)

44. Hülsheger, U.R., Anderson, N., Salgado, J.F.: Team-level predictors of innovation at work: a comprehensive meta-analysis spanning three decades of research. J. App. Psychol. 94(5), 1128 (2009)

45. Stanton, N.A., Allison, C.K.: Driving towards a greener future: an application of cognitive work analysis to promote fuel-efficient driving. Cognit. Technol. Work 22, 125-142 (2020)

46. Nielsen, J.: Iterative user-interface design. Computer 26(11), 32-41 (1993) 